\title{
O ENSINO DE BOTÂNICA NO LITORAL DO PARANÁ E AS IMPLICAÇÕES DA ARBORIZAÇÃO URBANA
}

\author{
Lenir Maristela Silva ${ }^{1}$, Bruna Farina², Josiane Ferreira Gomes Lourenço ${ }^{3}$
}

\section{RESUMO}

O conhecimento da biodiversidade de forma mais intensa pode contribuir muito com a conservação desta, afinal é muito mais provável que se proteja o que se conhece do que o que não se conhece. Na perspectiva da arborização urbana tem-se dois aspectos importantes com relação ao conhecimento da biodiversidade. O primeiro é que a arborização urbana pode contribuir para o conhecimento da biodiversidade local e o segundo aspecto é que quando a população tem percepção da biodiversidade local ela pode cuidar mais das árvores urbanas e, provavelmente, não se incomodar tanto com questões como rachaduras em calçadas, folhas caídas, dentre outros problemas decorrentes. Diante disso, o presente estudo investigou como tem acontecido o ensino do conhecimento sobre as plantas nas escolas públicas de educação básica do litoral do Paraná. Constatou-se que ainda é muito incipiente o ensino do conhecimento sobre as árvores da região nas escolas da educação básica. Evidenciou-se também que a arborização urbana contribui para o conhecimento das espécies pelos estudantes e professores o que justifica a importância de se arborizar com nativas.

Palavras-chave: biodiversidade; conservação; educação básica

\section{THE TEACHING OF BOTANY AT SCHOOLS ALONG THE COAST OF PARANÁ, AND THE IMPLICATIONS OF URBAN FORESTRY}

\section{ABSTRACT}

When citizens are aware of the meaning of biodiversity they will contribute to its conservation, since it is more likely for people to protect what they know well. In relation to urban Forestry, two important aspects of knowledge of biodiversity should be pointed out. The first is that knowing urban trees may lead to a greater knowledge of local biodiversity; the second is that, with better knowledge of these local aspects, citizens will be more willing to take care of urban trees and, probably, not be so bothered by issues like broken sidewalks or the accumulation of fallen leaves, or some other problems of this sort. Because of this, this study has investigated how the teaching on plants has been carried out at the public primary schools along the coast of the state of Paraná. The conclusion reached is that schools have just started teaching about the plants that are native to this region. There was also evidence that urban Forestry may have led students and teachers to a better undestanding of species, and this also stresses the importance of using native plants in urban Forestry.

Keywords: biodiversity; conservation; public primary schools

\footnotetext{
${ }^{1}$ Bióloga, UFPR, lenirsilva@ufpr.br

${ }^{2}$ Licencianda em Ciências, UFPR, brunafarina@gmail.com

${ }^{3}$ Licencianda em Ciências, UFPR, jolourenco2009@hotmail.com
} 


\section{INTRODUÇÃO}

Considerando um dos princípios fundamentais da educação que é a percepção crítica da realidade concreta, principalmente, àquela região em que a escola está instalada, já que oportuniza a mediação para o desenvolvimento local, é indispensável o reconhecimento do território nas suas múltiplas dimensões. O conhecimento da biodiversidade de forma mais intensa pode contribuir muito com a conservação desta, afinal é muito mais provável que se proteja o que se conhece do que o que não se conhece. Evidentemente, não é só a questão da conservação que está em jogo, mas principalmente, o fato de que o conhecimento da biodiversidade gera uma importante conseqüência para o desenvolvimento social local.

$\mathrm{Na}$ perspectiva da arborização urbana tem-se dois aspectos importantes com relação ao conhecimento da biodiversidade. O primeiro é que a arborização urbana pode contribuir para o conhecimento da biodiversidade local e o segundo aspecto é que quando a população tem percepção da biodiversidade local ela pode cuidar mais das árvores urbanas e provavelmente, não se incomodar tanto com questões como rachaduras em calçadas, folhas caídas, dentre outros problemas decorrentes.

Uma das grandes possibilidades que temos de aprender a conhecer a biodiversidade e desenvolver o sentimento de conservação é durante a Educação Básica. Os Parâmetros Curriculares Nacionais de Ciências Naturais apontam que a educação básica deve proporcionar o conhecimento dos diferentes Biomas, da caracterização dos estratos herbáceo, arbustivo e arbóreo, presentes em diferentes ambientes, do reconhecimento dos componentes vegetais das paisagens, da descrição e comparação de plantas significativas de determinados ambientes (BRASIL, 1998). Os meios didáticos para que os professores proporcionem esses conhecimentos para os estudantes pode ser diverso, incluindo, o livro didático e espaços vegetados próximos a escola.

Nos últimos anos, as coleções de obras didáticas não sofreram mudança substancial nos aspectos essenciais que derivam de fundamentos conceituais, os quais determinam as peculiaridades do ensino no campo das Ciências Naturais (MEGID NETO, FRACALANZA, 2003). Além disso, o livro didático utilizado nas escolas brasileiras raramente tem características regionais e desse modo, geralmente, as ilustrações da biodiversidade não são de plantas nativas. A exemplo, um dos livros utilizados no ensino fundamental nas escolas da rede estadual do Litoral do Paraná tem mais ilustrações de flora exótica do que nativa. O ciclo das gimnospermas é mostrado através de um esquema com imagens do Pinus sp. (VALLE, 2004) que é originário da América do Norte e, além disso, tem causado muitos problemas ambientais no Brasil devido ao seu potencial invasor.

Diante disso, o presente estudo investigou como tem acontecido o ensino do conhecimento sobre as plantas nas escolas públicas de educação básica do litoral do Paraná.

\section{MATERIAIS E MÉTODOS}

A pesquisa foi caracterizada como um levantamento exploratório descritivo através de entrevistas semiestruturadas. As entrevistas foram realizadas durante o ano de 2010 com os professores de Ciências e estudantes de $7^{\mathrm{a}}$ e/ou $8^{\mathrm{a}}$ séries do Ensino Fundamental das seguintes escolas do Litoral do Paraná: Colégio Estadual Sertãozinho, Colégio Estadual Gabriel de Lara, Colégio Estadual Professora Sully Rosa Vilarinho, Escola Estadual Deputado Aníbal khury, Colégio Estadual Moyses Lupion, Colégio Estadual 
Rocha Pombo, Colégio Estadual Estados Unidos da América e Colégio Estadual Tagaçaba Porto da Linha. As visitas às escolas foram previamente agendadas $\mathrm{e}$ autorizadas pelos diretores e conduzidas nos horários de intervalos de aula.

\section{RESULTADOS E DISCUSSÃO}

Quanto à formação dos professores que atuam nas disciplinas de Ciências, dez possuem licenciatura em Ciências, enquanto que outros três possuem graduação em: física, matemática, agronomia e psicologia. Isso indica à necessidade de formação complementar a esses professores além, de indicar um problema com relação a contratação de professores com formação na área que leciona.

Esse problema da formação dos professores de Ciências tem sido apontado em dados sobre a educação básica disponíveis no INEP (Instituto Nacional de Estudos e Pesquisas Educacionais Anísio Teixeira). Um levantamento de 2003 do INEP apontava que para atender a demanda do momento, seriam necessários 235 mil professores no ensino médio e 476 mil nas turmas de $5^{\mathrm{a}}$ a $8^{\mathrm{a}}$ série, totalizando 711 mil docentes. Mas nos anos anteriores haviam se formado apenas $457 \mathrm{mil} \mathrm{nos}$ cursos de licenciatura. Para tentar corrigir esse problema o MEC tem implantado diversos programas de incentivo a formação inicial e continuada. Dentre as áreas com maior escassez se encontra a área de Ciências tanto do ensino fundamental quanto no médio. Especificamente em Ciências do Ensino Fundamental, além da escassez outro problema que o INEP aponta é que a formação desses professores que tem se dado no âmbito das Ciências Biológicas, o que acaba causando deficiências no ensino de Física e Química. O INEP ainda menciona que dentre as áreas de Ciências da Natureza a única que não se encontra em situação crítica é a Biologia (ANDRÉ, 2002).

No que se refere mais especificamente ao ensino sobre as plantas, ficou evidenciada a falta de conhecimento sobre as plantas nativas da região pela maioria dos professores (Tabela 01). Vivências em programas de formação continuada de professores de ciências e biologia mostraram uma preferência por parte dos docentes em priorizar certos temas em sala de aula, deixando aqueles referentes à Botânica para as etapas finais (MARTINS e BRAGA, 1999 apud SILVA, 2008), sendo estes tratados de forma superficial, rápida e por meio da memorização de termos específicos (SILVA, 2008).

É interessante notar que as espécies citadas são todas arbóreas, ou seja, é muito mais fácil o conhecimento sobre árvores ao invés de arbustos e ervas. Segundo GOYA,1994 (apud MACHADO, SILVA e CASTRO, 2006), as árvores são apontadores marcantes que se possui de uma cidade, substituí-las é desvestir o local de parte de sua reminiscência, mudando significantemente sua imagem. Este mesmo autor lembrou que as árvores de cada cidade são parte integrante da memória urbana, sem a qual não se pode conjecturar o futuro. Isso demonstra o quanto a arborização urbana é importante para o conhecimento sobre as plantas.

O pouco conhecimento sobre a biodiversidade, mais especificamente sobre árvores nativas pelos professores de Ciências tem justificativa na própria fala destes, pois comentaram nas entrevistas que em sua formação, na maioria, não tiveram um bom aprendizado em botânica. Faltavam laboratórios, os professores eram mal preparados, o curso não era especifico em ciências ou biologia, não havia saídas de campo, a carga horária era pouca ou porque o assunto não foi abordado. $\mathrm{O}$ desapego pelas plantas por parte da maioria dos discentes e a carência de estudos atinentes ao Ensino de Botânica tanto no Ensino Fundamental como no Ensino Médio, tem alarmado muitos estudiosos Aoki (2005, apud NEVES e JOAQUIM, 2011).

Essa falta de conhecimento por parte dos professores acarreta a falta de conhecimento dos estudantes sobre as plantas do lugar (Tabela 02). Acarreta também a falta 
de interesse dos alunos pelo conteúdo ensinado pelos professores, por não terem um conhecimento aprofundado no assunto ou achar necessária uma identificação pelo nome científico das árvores, os professores ficam limitados aos conteúdos oferecidos pelos livros didáticos. Isso restringe muito a aprendizagem sobre a biodiversidade local porque os livros na maioria das vezes não trazem ilustrações sobre a biodiversidade local. Silva, Cavallet e Alquini (2005) mencionam que, na perspectiva da formação para a emancipação,é muito importante considerar o objeto de conhecimento (conteúdo) na sua relação com a realidade concreta.

Tabela 01. Plantas citadas como exemplos pelos professores de Ciências dos Colégios Estaduais de Matinhos, Morretes, Guaratuba, Pontal do Paraná, Antonina, Paranaguá e Guaraqueçaba - 2010

Table 01. Plants cited as examples for science teachers of public primary schools of Matinhos, Morretes, Guaratuba, Pontal do Paraná, Antonina, Paranaguá and Guaraqueçaba - 2010

\begin{tabular}{|c|c|c|}
\hline Colégio & Plantas citadas como nativas & Plantas realmente nativas na região \\
\hline 1 & $\begin{array}{l}\text { Caixeta, Guapê, Xaxim, Araçá, } \\
\text { Bromélias, Palmito Juçara, } \\
\text { Palmeiras, Sombreiro, Goiaba, } \\
\text { Banana, Limão, Comigo- } \\
\text { ninguém-pode. }\end{array}$ & $\begin{array}{l}\text { Caixeta, Araçá, Palmito Juçara, Xaxim, bromélias, } \\
\text { palmeiras }\end{array}$ \\
\hline 2 & $\begin{array}{l}\text { Caixeta, Aroeira, Jacatirão, Pau- } \\
\text { Brasil, } \quad \text { Guapuruvu, } \\
\text { Juçara, } \quad \text { Palmito } \\
\text { Araucária. }\end{array}$ & $\begin{array}{l}\text { Caixeta, Aroeira, Jacatirão, Guapuruvu, Palmito } \\
\text { Juçara, Canela, louro }\end{array}$ \\
\hline 3 & Guapê & \\
\hline 4 & $\begin{array}{l}\text { Ipê Amarelo, Peroba, Cedro, } \\
\text { Figueira, Angico. }\end{array}$ & Ipê Amarelo, cedro, figueira, peroba \\
\hline 5 & $\begin{array}{l}\text { Palmito Juçara, Aroeira, } \\
\text { Caixeta, Ipê, Pau Brasil }\end{array}$ & Palmito Juçara, Aroeira, Caixeta, Ipê \\
\hline 6 & $\begin{array}{l}\text { Palmito Juçara, Bromélia, } \\
\text { Orquídeas, Banana, Araçá, } \\
\text { Goiaba, Ipê, } \\
\text { Samambaia }\end{array}$ & $\begin{array}{l}\text { Palmito Juçara, Araçá, Ipê, Manacá, bromélia, } \\
\text { orquídeas, samambaia }\end{array}$ \\
\hline 7 & Nenhuma & Nenhuma \\
\hline 8 & $\begin{array}{l}\text { Jacatirão, } \quad \text { Ipê } \quad \text { Amarelo, } \\
\text { Guapuruvu, Canela }\end{array}$ & Jacatirão, Ipê Amarelo, Guapuruvu, canela \\
\hline
\end{tabular}

Alguns estudantes entrevistados quando inquiridos sobre que espécies nativas eles conheciam, perguntaram se era da cidade ou do mato. Isso demonstra também que o conceito de espécie nativa não é claro. Quando perguntados sobre o porquê da dúvida, eles responderam que eles conheciam mais as árvores da cidade. Bruzzo (2004 apud NEVES e JOAQUIM, 2011) defende o emprego de imagens para o ensino de ciências:Se existe uma juntura entre imagem e conhecimento na educação em biologia, talvez tenhamos que admitir que as imagens possam modificar a maneira de conhecer de uma determinada área de conhecimento e reconhecer que a imagem pode ter uma influência importante no aprendizado e na reflexão educativas. Esse é mais quesito 
que demonstra a importância da arborização urbana no conhecimento das crianças e adolescentes sobre as plantas.

O ensino de Botânica pode se tornar agradável aos estudantes. Uma atividade maçante para um adolescente, como montar um pequeno herbário, pode ser transformada em motivo de reuniões sociais e estreitar os laços de amizade entre os próprios alunos e professores. Até a montagem de um herbário virtual, com fotos produzidas pelos estudantes pode se tornar algo estimulante para todos e com vantagem de não cheirar naftalina. Agendar passeios em matas, ou mesmo aos Jardins Botânicos, pode se tornar algo extremamente educativo, não só em relação ao Reino Vegetal, como também a Educação Ambiental. Aliás, o ensino de Botânica tem que ter uma visão ambientalista, além de econômica, farmacêutica, naturalista, dentre outras (MINHOTO, 2003). Nesse sentido, se a arborização urbana comportar espécies arbóreas nativas da região, um passeio pelas ruas nos arredores da escola seria uma aula muito interessante para o conhecimento da flora nativa.

Tabela 02. Plantas citadas como exemplos pelos estudantes de $7^{\mathrm{a}}$ e $8^{\mathrm{a}}$ dos Colégios Estaduais de Matinhos, Pontal do Paraná, Guaratuba, Antonina, Morretes, Paranaguá e Tagaçaba - 2010

Table 02. Plants cited as examples for students of public primary schools of Matinhos, Pontal do Paraná, Guaratuba, Antonina, Morretes, Paranaguá and Tagaçaba - 2010

\begin{tabular}{|c|c|c|}
\hline Colégio & Plantas citadas como nativas & Plantas realmente nativas da região \\
\hline 1 & $\begin{array}{l}\text { Araucária, Ipê, Ameixa, Laranja, Orquídea, } \\
\text { Samambaia, Banana, Goiaba, Araçá, Limão, } \\
\text { Coqueiro, Pitanga, Amora, Abacate, Manga. }\end{array}$ & Ipê, Araçá, orquídea, samambaia, pitanga \\
\hline 2 & $\begin{array}{l}\text { Palmeira real, Sombreiro, Pinheiro do Paraná, Pau } \\
\text { Brasil, Aroeira, Coqueiro. }\end{array}$ & Aroeira \\
\hline 3 & $\begin{array}{l}\text { Guapê, Goiaba, Maracujá, Melancia, Pitanga, } \\
\text { Franboiã, Sombreiro, Limão, Abacate, Goiaba, } \\
\text { Erva Mate }\end{array}$ & Pitanga \\
\hline 4 & Limão, Laranja, Goiaba. & - \\
\hline 5 & $\begin{array}{l}\text { Hortelã, Rosa, Sombreiro, Palmito Juçara, Café, } \\
\text { Banana, Laranja, Coqueiro, Goiaba }\end{array}$ & Palmito Juçara \\
\hline 6 & $\begin{array}{l}\text { Comigo ninguém pode, Violeta, Samambaia, Pau } \\
\text { Brasil, Jaca, Jasmim, Orquídea, Beijinho, Rosa }\end{array}$ & Samambaia \\
\hline 7 & $\begin{array}{l}\text { Coqueiro, Jabuticaba, Goiaba, Jaca, Mimosa, } \\
\text { Babosa, Pata-de-Vaca }\end{array}$ & - \\
\hline 8 & $\begin{array}{l}\text { Canela, Eucalipto, Palmito Juçara, Palmito } \\
\text { Pupunha, Peroba }\end{array}$ & Canela, Palmito Juçara \\
\hline
\end{tabular}

Dentre os materiais utilizados pelos professores, o mais citado é o livro didático (Tabela 3). Os livros didáticos utilizados aqui na região não possuem ilustração com foco na flora local, o que dificulta mais ainda o ensino das plantas regionais. 
Tabela 03. Materiais didáticos utilizados pelos professores de Colégios Estaduais de Matinhos, Pontal do Paraná, Guaratuba, Antonina, Morretes, Paranaguá e Tagaçaba - 2010 para apresentação do conteúdo de botânica

Table 03. Instructional materials used by teachers of public primary schools of Matinhos, Pontal do Paraná, Guaratuba, Antonina, Morriston, Paranaguá and Tagaçaba - 2010 for presenting the contents of botanical

\begin{tabular}{l|c|c|c|c}
\hline \multicolumn{1}{c|}{ Colégio } & Livro Didático & Pesquisa & Saída de Campo & \\
\hline 1 & $\mathrm{X}$ & $\mathrm{X}$ & $\mathrm{X}$ \\
\hline 2 & $\mathrm{X}$ & $\mathrm{X}$ & $\mathrm{X}$ \\
\hline 3 & $\mathrm{X}$ & $\mathrm{X}$ & $\mathrm{X}$ \\
\hline 4 & $\mathrm{X}$ & $\mathrm{X}$ & $\mathrm{X}$ \\
\hline 5 & $\mathrm{X}$ & $\mathrm{X}$ & $\mathrm{X}$ \\
\hline 6 & $\mathrm{X}$ & $\mathrm{X}$ & \\
\hline 7 & $\mathrm{X}$ & & \\
\hline 8
\end{tabular}

A maioria dos professores entrevistados não aproveita o entorno da escola para realizar aulas expositivas sobre as árvores, pois dentro das instituições na maioria não há espécies nativas, ou são poucas espécies vegetais nativas encontradas. Quando há presença de plantas, são geralmente exóticas. Algumas espécies exóticas podem ser invasoras e não possuírem boa relação com as nativas. $\mathrm{O}$ emprego de espécies da vegetação nativa na arborização de parques, praças, jardins e passeios urbanos parece ser uma prática desejável, com enormes proveitos ambientais, estéticos e culturais para as cidades (MACHADO; SILVA; CASTRO, 2006). Nesse sentido indagaram-se os professores sobre a importância das espécies nativas na aprendizagem de seus alunos, todos acham essencial que os estudantes conheçam um número mínimo de vegetação nativa pelo nome comum, para sensibilização da preservação do meio vegetal e para que valorizem a identidade do local em que vivem.

O Conhecimento sobre plantas ainda é muito incipiente nas escolas da educação básica. A arborização urbana nas vias públicas contribui para o conhecimento das espécies pelos estudantes e professores o que justifica a importância de se arborizar com nativas. Mesmo que os gestores municipais não tenham interesse em substituir as árvores exóticas por espécies nativas, o que também além de trabalhoso pode onerar o município é possível dar uma característica mais brasileira as espécies realizando uma arborização ecológica. Nesse sentido, Reis, et al., (2003), sugerem o plantio de epífitas sobre as árvores exóticas, como bromélias e orquídeas. A presença de epífitas caracteriza a identidade da vegetação brasileira, pois a floresta tropical originalmente ocupava cerca de $60 \%$ do território nacional e a presença de epífita nesse tipo de floresta é marcante devido a elevada umidade relativa presente (SILVA, 2011).

Mas além da arborização das vias públicas é consideravelmente importante a arborização dos pátios escolares com espécies nativas para contribuir com o conhecimento das espécies arbóreas pelos estudantes. Neste estudo não inventariamos as espécies nos pátios, mas de uma observação genérica pode-se inferir que há pouquíssimas espécies nativas nos pátios dessas escolas. Cadorin, et al (2011) analisou a flora arbórea do pátio de quatro escolas de Pato Branco/PR e identificou o predomínio de espécies exóticas em relação às nativas. Das 49 espécies identificadas por Cadorin et al (2011) cerca 21 eram nativas do Brasil, mas apenas 11 pertencente ao Bioma local (Floresta Ombrófila Mista). 
Ficou bastante visível a falta de conhecimento sobre as plantas nativas da região pela maioria dos professores. As espécies citadas, mesmo as não nativas, são todas arbóreas, ou seja, é muito mais fácil o conhecimento sobre árvores ao invés de arbustos e ervas. O pouco conhecimento sobre a biodiversidade, mais especificamente sobre árvores nativas pelos professores de Ciências tem justificativa na própria fala destes, pois comentaram nas entrevistas que em sua formação, na maioria, não tiveram um bom aprendizado em Botânica. O conceito de espécie nativa não é claro. Quando perguntados sobre o porquê da dúvida, eles responderam que eles conheciam mais as árvores da cidade, inclusive, acreditando serem nativas.

Dentre os materiais utilizados pelos professores, o mais citado é o livro didático. Os livros didáticos utilizados na região não possuem ilustração com foco na flora local, o que dificulta mais ainda o ensino das plantas regionais.

\begin{abstract}
A maioria dos professores entrevistados não aproveita o entorno da escola para realizar aulas sobre as árvores, pois na maioria das instituições não há árvores nativas, ou são poucas espécies vegetais nativas encontradas. Quando há presença de plantas, são geralmente exóticas.

O Conhecimento sobre plantas ainda é muito incipiente nas escolas da educação básica. A arborização urbana nas vias públicas contribui para o conhecimento das espécies pelos estudantes e professores o que justifica a importância de se arborizar com nativas. Assim como é consideravelmente importante a arborização dos pátios escolares com espécies nativas para contribuir com o conhecimento das espécies arbóreas pelos estudantes.
\end{abstract}

\section{REFERÊNCIAS}

ANDRÉ , Marli Eliza Dalmazo Afonso (ORG.). Formação de professores no Brasil (1990-1998) Brasília : MEC/Inep/Comped, 2002. 364 p.

BRASIL. Secretaria de Educação Fundamental. Parâmetros curriculares nacionais: Ciências Naturais / Secretaria de Educação Fundamental. Brasília: MEC /SEF, 1998.138 p.

CADORIN, D. A. HASSE, I.; SILVA, L. M.; BETT, C. F. Características da flora arbórea de quatro escolas de Pato Branco-PR. REVSBAU, Piracicaba - SP, v.6, n.2, p.104-124, 2011.

MACHADO, R. R. B.; SILVA J. A. A.; CASTRO, A.A.J.F. Árvores nativas para a arborização de Teresina, Piauí. Revista da Sociedade Brasileira de Arborização Urbana, Volume 1, Número 1, 2006.

MEGID NETO, J, FRACALANZA, H., O livro didático de ciências: problemas e soluções. Ciência \& Educação, v. 9, n. 2, p. 147-157, 2003.

MINHOTO, M.J. Ausência de músculos ou porque os professores de biologia odeiam botânica. Disponível em< www.botanicasp.org.br/educacao/Ausencia.pdf> Acesso em setembro de 2003.

NEVES, F. A. S.; JOAQUIM, W. M. A construção do conhecimento sobre plantas carnívoras pelos alunos da $6^{\mathrm{a}}$ série das redes estadual e municipal de ensino de São José dos Campos . In: XII Encontro Latino Americano de Iniciação Científica e VIII Encontro Latino Americano de Pós-Graduação - Universidade do Vale do Paraíba. Anais... Juiz de Fora/MG, 2011.

REIS, A.; ANJOS, A.; LESSA, A. P.; BECHARA, F. Critérios para a seleção de espécies na arborização ecológica. Sellowia, Itajaí, v. 53, n. 55 pág. 51-67, 2003.

SILVA, L. M. Percepção da flora por calouros do ensino superior: a importância da educação ambiental. Revista brasileira de educação ambiental (Online), v. 6, p. 76-84, 2011.

SILVA, L. M.; CAVALLET, V. J.; ALQUINI, Y. Contribuição à reflexão sobre a concepção de natureza no ensino de botânica. Revista Brasileira de Estudos Pedagógicos, Brasília, v. 86, n. 213/214, p. 110-120, 2005.

SILVA, P. G. P. O ensino da botânica no nível fundamental: um enfoque nos procedimentos metodológicos. Bauru/SP, 2008. Tese (Doutorado em Ensino de Ciências). Universidade Estadual Paulista/Faculdade de Ciências.

VALLE, C. Vida e Ambiente. 6 $6^{\text {a }}$ série. Curitiba: Positivo, 2004 (Coleção Ciências). 